\title{
Knowledge, perception and practice of self- medication among premedical and basic science undergraduate medical students
}

\author{
P Ravi Shankar ${ }^{1,2}$, Arun K Dubey ${ }^{3}$, Neelam R Dwivedi',5, A Nandy ${ }^{6,7}$, B Barton ${ }^{8}$ \\ ${ }^{1}$ Professor of Pharmacology, Chair, Curriculum Committee, ${ }^{2}$ Assistant Dean, Medical Education, ${ }^{3}$ Dean, Basic Medical \\ Sciences, ${ }^{4}$ Profession of Introduction to Clinical Medicine, ${ }^{5}$ Director, Standardized Patient Program, ${ }^{6}$ Professor, \\ Department of Microbiology, ${ }^{7}$ Assistant Dean Student Affairs, ${ }^{8}$ Dean, Department of Premedical Science, Xavier \\ University School of Medicine, Oranjestad, Aruba, Kingdom of the Netherlands
}

Background: Responsible self-medication is an important component of self-care. Medical students are in a unique position as they cannot yet legally prescribe medicines but their knowledge about and exposure to medicines increase as they progress through their course. Xavier University School of Medicine admits students mainly from the United States, Canada and other countries to the undergraduate medical course. Aims and Objectives: The present study was carried out to study the knowledge, perceptions and practice of self-medication among premedical and undergraduate medical students. Materials and Methods: The study was conducted during June and July 2016 using a questionnaire which had been used previously. Knowledge and perceptions were studied by noting the respondents' degree of agreement with a set of 40 statements. The use of selected classes of medicines for selfmedication during the preceding one-year period was studied. The knowledge, perception and total scores were calculated and compared among different subgroups of respondents. Age, gender, nationality and semester of study of the respondents were noted. Results: Eightyfive of the 125 students enrolled (69.1\%) participated. The mean knowledge, perception and total scores were 73.45, 62.75 and 136.2 (maximum possible scores were 105, 95 and 200 respectively). There was no significant difference in scores among subgroups of respondents. Analgesics, skin ointments, antipyretics and anti-allergics were commonly used for self-medication. Over half the respondents had used some form of self-medication during the preceding year. Conclusion: The present study provides preliminary information regarding self-medication practices among both premedical and basic science medical students. Further studies on factors influencing and information sources used during selfmedication can be conducted.

Key words: Analgesics, Antibiotics, Caribbean, Medical students, Medicines, Rational use of medicines, Self-medication

\section{INTRODUCTION}

The World Health Organization (WHO) defines self-care as the primary public health resource in the healthcare system. ${ }^{1}$ Self-medication constitutes an important part of self-care. Improvements in knowledge levels, socioeconomic status and education may provide the foundation for successful self-medication. The booklet on self-medication published by the WHO mentions that self-medication involves the use of medicinal products by the consumer to treat self-recognized disorders or symptoms or the intermittent or continued use of a medication which was prescribed by a physician for a chronic or recurring disease or symptoms. ${ }^{1}$ Inappropriate self-medication wastes resources, increases the likelihood of adverse drug reactions and may also be involved in antimicrobial resistance. ${ }^{2}$ 
Medical students occupy a unique position; they cannot yet legally prescribe medications but as they progress through the course of study they may acquire greater knowledge about medicines and be more capable regarding their rational use. Self-medication is more likely among medical students as they have easy access to drug information sources, and their knowledge to self-diagnose and selfmedicate increases as they progress through the course.,3 They also have easier access to medicines both through physicians samples provided by pharmaceutical companies and the 'white coat' also ensures easy access to medicines.

Self-medication practices among medical students have been previously studied elsewhere. In a study conducted in Jordan, a high prevalence of self-medication was noted among both medical and pharmacy students. ${ }^{4}$ Analgesics and antibiotics were commonly used and the reasons included previous experience of the same disease, the ailment being regarded as minor and the perception of having enough medical knowledge to manage the condition and for using the medicine. Misuse of antibiotics, including their use for selfmedication is an important reason for antibiotic resistance. A study carried out in Saudi Arabia showed deficiencies in the knowledge, attitude and practice of medical students with regard to use of antibiotics for upper respiratory tract infections (URTI). ${ }^{5}$ About $18 \%$ of respondents were of the opinion that antibiotics could be used for viral infections and self-medication without a prescription was seen in nearly half the cases. Female medical students had better knowledge and knowledge increased with the study year. The authors have explained this by stating that women are more likely to spend time with their mothers and were involved in raising children. This may translate into greater knowledge about childhood diseases and the medications, including antibiotics taken by children. Self-medication was studied among students of a private medical institute in India. ${ }^{6}$ Nearly $72 \%$ of respondents had self-medicated during the preceding one year and the prevalence was more among first year students.

Xavier University School of Medicine (XUSOM) is a private medical school admitting students from the United States (US), Canada and other countries. Students complete the basic sciences in an integrated, organ system-based manner at XUSOM, Aruba and then do their clinical rotations in affiliated hospitals in the US and Canada. At the institution a semester of study is of 15 weeks duration and there are three student intakes a year in January, May and September. The institution also admits students to the premedical program of four semester (16 months) duration. The premedical program prepares students who have completed their high school education for admission to medical school. Recently educational initiatives to introduce and strengthen rational use of medicines by students have been undertaken. ${ }^{7}$
Self-medication practices among the premedical and basic science medical students at the institution have not yet been studied. Hence, the present study was carried out to study knowledge and perception about self-medication among premedical and undergraduate basic science medical students and note differences in the scores, if any, among various groups of respondents. The use of medicines for self-medication by the respondents during the preceding one-year period was also studied.

\section{MATERIALS AND METHODS}

The present study was conducted among pre-medical and basic science undergraduate medicalstudents during June and the first week of July 2016. The premedical course prepares students for admission to the medical program and though students do not learn pharmacology they may have a certain degree of knowledge about medicines as many of their parents are doctors and they also interact with the undergraduate medical students. The six semesters of the basic sciences is followed by clinical rotations in the US and/or Canada. We could not include clinical students in the study due to logistic reasons. Students were informed of the aims and objectives of the study and invited to participate. Written informed consent was obtained from all participants. The study was approved by the institutional review board of the institution vide notification XUSOM/ $\mathrm{IRB} / 2016 / 02$.

Information about knowledge, perception and practice of self-medication was studied using a questionnaire which had been used previously in a study conducted in Western Nepal. ${ }^{8}$ Knowledge and perception was studied by noting the respondents' degree of agreement with a set of 40 statements using a Likert scale. The knowledge, perception and total score was calculated by adding the scores of different individual statements. Certain statements were negatively worded and their scores reversed while calculating the total score. The practice of self-medication was studied by noting the respondents' pattern of use of selected groups of medicines during the preceding one-year period. Analgesics, skin ointments, antipyretics, antiallergics and antibiotics were the groups of medicines whose use was studied.

Age, gender, nationality and semester of study of the respondents were noted. The normality of distribution of the knowledge, perception and total scores was studied using the one-sample Kolmogorov-Smirnov test. The mean scores were compared among different subgroups of respondents using appropriate statistical tests $(\mathrm{p}<0.05)$. The mean scores of individual statements was also calculated. Cronbach's alpha was calculated as a measure of internal consistency of the questionnaire. The values 
for statements dealing with knowledge, with perception and for all statements with a Likert type scoring scale was calculated. Free text comments were noted.

\section{RESULTS}

Eighty-five of the total 123 (69.1\%) premedical and basic science medical students enrolled at the institution in Aruba during the Summer 2016 semester participated. Table 1 shows the demographic characteristics of the respondents. Some respondents did not provide information about certain demographic characteristics.

\begin{tabular}{lc}
$\begin{array}{l}\text { Table 1: Respondents' demographic } \\
\text { characteristics }\end{array}$ \\
\hline Characteristic & Number (percentage) N=85 \\
\hline Age (in years) & \\
$<20$ & $14(16.5)$ \\
$20-25$ & $36(42.4)$ \\
$25-30$ & $26(30.6)$ \\
$>30$ & $6(7.1)$ \\
Gender & \\
Male & $45(52.9)$ \\
Female & $38(44.7)$ \\
Nationality & \\
United States & $32(37.6)$ \\
Canadian & $23(27.1)$ \\
Others & $16(18.8)$ \\
Semester of study & \\
Premed 1 & $2(2.4)$ \\
Premed 3 & $14(16.5)$ \\
Premed 4 & $1(1.2)$ \\
MD 1 & $10(11.8)$ \\
MD 2 & $13(15.3)$ \\
MD 3 & $23(27.1)$ \\
MD 5 & $11(12.8)$ \\
MD 6 & $11(12.8)$ \\
\hline
\end{tabular}

The knowledge and perception scores were noted to be normally distributed on conducting the one sample Kolmogorov-Smirnov (K-S) test. Hence mean was used as the measure of central tendency. The mean knowledge, perception and total scores were 73.45, 62.75 and 136.2. The maximum possible scores being 105, 95 and 200 respectively. Table 2 shows the mean knowledge, perception and total scores among different subgroups of students. There was no significant difference in the scores among different subgroups of students.

Table 3 shows the mean scores of individual statements. The scores of certain statements were reversed while calculating the total score. The mean scores of statements dealing with the importance of enquiring about self-medication while taking a medication history, the possibility of self-medication interfering with the action of prescription drugs and self-medication with antibiotics being an important cause of resistance were high (around 4). Table 4 shows the stated frequency of use of selected classes of medicines by the respondents over the preceding one-year period. Analgesics, skin ointments, antipyretics and anti-allergics were commonly used. Self-medication with antibiotics was also not uncommon. Forty-three of the total of 85 respondents $(50.6 \%)$ had used some form of self-medication during the preceding one year period. The Cronbach's alpha value for statements dealing with knowledge was 0.679, for those dealing with perception was 0.594 and for the total was 0.777 .

Many respondents mentioned that the topic of study was interesting and they do sometimes, self-medicate themselves especially with pain killers. A respondent stated that self-

\begin{tabular}{|c|c|c|c|c|c|c|}
\hline Characteristic & Knowledge score & $p$ value & Perception score & $p$ value & Total score & $p$ value \\
\hline \multicolumn{7}{|l|}{ Age group } \\
\hline Below 20 years & 72.28 & \multirow[t]{4}{*}{0.106} & 61.86 & \multirow[t]{4}{*}{0.209} & 134.14 & \multirow[t]{4}{*}{0.092} \\
\hline 20 to 25 years & 72.72 & & 62.42 & & 136.14 & \\
\hline 25 to 30 years & 74.81 & & 62.86 & & 137.77 & \\
\hline Above 30 years & 80.67 & & 68.5 & & 149.17 & \\
\hline \multicolumn{7}{|l|}{ Gender } \\
\hline Male & 72.47 & \multirow[t]{2}{*}{0.177} & 62.49 & \multirow[t]{2}{*}{0.585} & 134.95 & \multirow[t]{2}{*}{0.281} \\
\hline Female & 74.92 & & 63.31 & & 138.23 & \\
\hline \multicolumn{7}{|l|}{ Nationality } \\
\hline American & 73.06 & \multirow[t]{3}{*}{0.483} & 63.56 & \multirow[t]{3}{*}{0.543} & 136.62 & \multirow[t]{3}{*}{0.781} \\
\hline Canadian & 75.65 & & 62.17 & & 137.63 & \\
\hline Others & 73.25 & & 61.44 & & 134.69 & \\
\hline \multicolumn{7}{|l|}{ Semester } \\
\hline Premed & 72.53 & \multirow[t]{6}{*}{0.253} & 61.94 & \multirow[t]{6}{*}{0.448} & 134.47 & \multirow[t]{6}{*}{0.293} \\
\hline MD 1 & 72.60 & & 61.5 & & 134.10 & \\
\hline MD 2 & 75.38 & & 61.92 & & 137.31 & \\
\hline MD 3 & 75.48 & & 64.69 & & 140.17 & \\
\hline MD 5 & 68.45 & & 60.27 & & 128.73 & \\
\hline MD 6 & 74.09 & & 64.54 & & 138.64 & \\
\hline
\end{tabular}


Table 3: Mean scores of individual statements

\begin{tabular}{|c|c|}
\hline Statement & $\begin{array}{l}\text { Mean } \\
\text { score }\end{array}$ \\
\hline Self-medication can readily relieve acute medical problems & 3.38 \\
\hline Self-medication is favored by a person'sfamily and society & 3.29 \\
\hline Self-medication is promoted by the easy availability of medicines/drugs & 3.89 \\
\hline Self-medication eliminates the need to visit the doctor for minor illnesses & 3.72 \\
\hline Self-medication is economical & 3.40 \\
\hline Self-medication is influenced by exposure to drug advertisements in the media & 3.70 \\
\hline High levels of education and professional status have been mentioned as predictive factors favoring self-medication & 3.07 \\
\hline Mild illnesses have to be treated by self-medication* & 2.92 \\
\hline Previous experience of treating similar illness can promote self-medication & 3.82 \\
\hline Lack of availability of healthcare personnel is a major cause for self-medication & 3.87 \\
\hline Antimicrobials are the commonest class of medicines used for self-medication* & 3.13 \\
\hline Self-medication can save the time spend waiting to see a doctor & 3.46 \\
\hline Self-medication is purchasing medicines from a medicine shop without a doctor's prescription & 3.29 \\
\hline Severe adverse reactions may result from self-medication & 3.80 \\
\hline Self-medication carries the risk of using wrong medicines & 4.06 \\
\hline I favor self-medication for poor persons & 2.61 \\
\hline Self-medication promotes drug dependence* & 3.12 \\
\hline Self-medication may sometimes lead to missing the disease diagnosis. & 3.89 \\
\hline Self-medication cancure all types of diseases* & 3.87 \\
\hline Painkillers may be used for self-medication & 3.21 \\
\hline Self-medication is a widely accepted and reliable way for curing/managing diseases & 2.62 \\
\hline Self-medication is suitable for common cold & 3.68 \\
\hline Diarrhea can be easily cured through self-medication & 3.21 \\
\hline Drug interactions can occur due to self-medication & 3.86 \\
\hline Pregnant woman can take iron and folic acid without any risk as self-medication & 2.96 \\
\hline Vitamins and tonics are suitable for self-medication & 3.28 \\
\hline All herbal medicines are safe for use as self-medication* & 3.59 \\
\hline Self-medication allows students to be easily treated for any disease & 2.62 \\
\hline Headache is the commonest indication for self-medication & 3.48 \\
\hline Indigestion problems can be easily handled by self-medication & 3.19 \\
\hline Self-medication can even save lives in acute conditions & 3.09 \\
\hline Self-medication is more likely if the parents of the students are health care professionals & 3.25 \\
\hline Self-medication can give greater profit to pharmaceutical companies & 3.45 \\
\hline Self-medication is appropriate for short term relief of symptoms where accurate diagnosis is not necessary & 3.35 \\
\hline Availability of transport may influence practice of self-medication & 3.50 \\
\hline Self-medication is less common in developed nations compared to developing ones & 2.96 \\
\hline Extensive use of self-medication can potentially reduce doctor's workload & 2.79 \\
\hline As a future doctor you must recognize the importance of questioning patients about self-medication when taking a drug history & 4.15 \\
\hline Self-medication can interfere with the action of prescription drugs or treatments & 4.00 \\
\hline Self-medication with antibiotics is a common cause for antibiotic resistance & 3.95 \\
\hline
\end{tabular}

\begin{tabular}{|c|c|c|c|c|c|}
\hline Frequency of use & Analgesics & Skin ointments & Antipyretics & Anti-allergics & Antibiotics \\
\hline Once & 26 & 36 & 40 & 37 & 42 \\
\hline Every few weeks & 13 & 9 & 6 & 10 & 5 \\
\hline Every few months & 15 & 7 & 9 & 6 & 11 \\
\hline More than 5 times per year & 10 & 4 & 7 & 5 & 2 \\
\hline Nearly all the time & 5 & 8 & 2 & 6 & 0 \\
\hline
\end{tabular}

medication is fine as long as the patient understands why a particular medication being taken is necessary. Another respondent mentioned that antibiotic resistance is a big problem both due to patients self-diagnosing and taking antibiotics without valid reasons and also due to doctors misdiagnosing and prescribing antibiotics.

\section{DISCUSSION}

The response rate was good for a voluntary survey. The mean knowledge, perception and total scores were 73.45 , 62.75 and 136.2 (maximum possible scores being 105, 95 and 200 respectively). The scores obtained in the present study were toward the middle of the range. The scores of some individual statements were low. Free text 
comments were obtained and the internal consistency of the questionnaire as measured by Cronbach's alpha values was acceptable though, lower for statements dealing with perception. Self-reported information about the respondents' self-medication practices during the one year period preceding the study was also obtained.

Knowledge, attitude and practice (KAP) of self-medication has been studied among university students, including health professions students in other countries. At the Manipal College of Medical Sciences (MCOMS), Pokhara, Nepal a cross-sectional study was conducted among basic science undergraduate medical students to note their KAP about self-medication. ${ }^{8}$ The mean knowledge, attitude and total scores in the study were 74.54,67.19 and 141.73. The scores were comparable to that obtained in the present study. In the study conducted at Pokhara, the scores were higher among fourth semester students compared to the second semester and there were differences in knowledge and total scores among students of different nationalities. ${ }^{8}$ In the present study scores were generally higher among older respondents, female respondents and respondents belonging to higher semesters though the differences were not significant. A study conducted among first year medical students at Bahrain showed that respondents' knowledge about appropriate self-medication was poor but they showed adequate knowledge about the benefits and risks of self-medication. ${ }^{9}$ Majority of the respondents had a positive attitude toward self-medication and it was practiced by $44.8 \%$ of the respondents. This is slightly lower than the percentage of respondents who reported using some form of self-medication in the present study. In Bahrain, analgesics were the most common medicines used for self-medication similar to the present study. A study conducted among medical students in South India found that self-medication was very common with the prevalence reported to be $92 \%{ }^{3}$ Common cold, fever and headache were the most common ailments and antipyretics, analgesics, antihistamines and antibiotics were most commonly used.

The scores of certain statements in the present study were low. A previous study had examined perceptions toward and practice of self-medication among medical students in coastal South India. ${ }^{10}$ The prevalence of selfmedication was $78.6 \%$ and a greater number of females were self-medicating compared to males. Antipyretics were the drug category most commonly used. Selfmedication practices and the impact of increasing level of knowledge on the same was studied in Jordan. ${ }^{4}$ Over $78 \%$ of the respondents had self-medicated and this was more common among pharmacy students. Analgesics and antibiotics were most frequently used. Students referred to the information leaflet in the drug package, pharmacist and university courses to obtain information about the medicines. Self-medication practices and risk factors for self-medication was studied among medical students in Belgrade, Serbia. ${ }^{11}$ Nearly $80 \%$ of students in this study reported using self-medication which was higher than that reported in our study. Analgesics were most frequently used and the independent risk factors for self-medication were possession of a home pharmacy, lower levels of father's education, consumption of alcoholic beverages, reduced physical activity among others.

Aruba is a constituent country of the kingdom of the Netherlands and has strict regulations regarding the availability of medicines in pharmacies. Prescription-only medicines cannot be purchased without a prescription. The school admits students from the United States, Canada, Caribbean countries and other developing nations to the MD course. Students may be bringing medicines with them when they travel to the island. The school does not run clinical facilities and so students do not have access to the hospital pharmacy and do not obtain pharmaceutical samples while on the island. The knowledge and perception of students did increase as they progressed across the course. Sessions on rational use of medicines, patient counseling and personal drug selection are conducted for students and this may have partly accounted for their high scores with regard to the importance of obtaining a self-medication history and about the consequences of improper dealing with selfmedication. We were not able to locate previous studies among medical students in the Caribbean on searching the PubMed and Google Scholar databases.

The response rate in the present study was good and the questionnaire had been used previously and the internal consistency of the questionnaire as measured by Cronbach's alpha was good. However, information was collected only using a questionnaire and was not triangulated with that obtained from other sources. It is possible that recall bias may have occurred regarding the use of medicines for self-medication during the year preceding the study. Though respondents were requested to independently complete the questionnaire the possibility of discussions and interactions between respondents could not be ruled out.

\section{CONCLUSION}

The present study provides preliminary information regarding self-medication practices among both premedical and basic science undergraduate medical studentsat XUSOM, Aruba. There were no significant difference in knowledge and perception among different groups 
of students. Further studies on factors influencing self-medication and information sources used can be conducted. Similar studies can be conducted among students in other Caribbean medical schools.

\section{ACKNOWLEDGMENTS}

The authors acknowledge all students who participated in the present study.

\section{REFERENCES}

1. World Health Organization. Guidelines for the regulatory assessment of medicinal products for use in self-medication. (2000) [cited $2016 \mathrm{Jul}$ 14]. Available from: http://apps.who.int/ medicinedocs/pdf/s2218e/s2218e.pdf.

2. James $H$, Handu SS, Khalid AJ, Khaja A, Otoom $S$ and Sequeira RP. Evaluation of the knowledge, attitude and practice of self-medication among first-year medical students. Med Princ Pract 2006;15:270-275.

3. Badiger S, Kundapur R, Jain A, Kumar A, Pattanshetty S, Thakolkaran N, et al. Self-medication patterns among medical students in South India.Australas Med J 2012;5:217-220.

4. Alkhatatbeh MJ, Alefan $Q$ and Alqudah MA. High prevalence of self-medication practices among medical and pharmacy students: a study from Jordan. Int J Clin Pharmacol Ther 2016;54:390-398.

5. Harakeh S, Almatrafi M, Ungapen H, Hammad R, Olayan F, Hakim R, et al. Perceptions of medical students towards antibiotic prescribing for upper respiratory tract infections in Saudi Arabia. BMJ Open Respir Res 2015;2:e000078.

6. Kasulkar AA and Gupta M. Self-medication Practices among Medical Students of a Private Institute. Indian J Pharm Sci 2015;77:178-182.

7. Shankar PR. Seven Semesters of Personal Drug Selection in a Caribbean Medical School. Education in Medicine Journal 2015;7;e80-e82.

8. Gyawali S, Shankar PR, Poudel PP and Saha A. Knowledge, Attitude and Practice of Self-medication among Basic ScienceUndergraduate Medical Students in a Medical School in Western Nepal. J Clin Diagn Res 2015;9(12):FC17-FC22.

9. James H, Handu SS, Al Khaja KA, Otoom S and Sequeira RP. Evaluation of the knowledge, attitude and practice of selfmedication among first-year medical students. Med Princ Pract 2006;15:270-275.

10. Kumar N, Kanchan T, Unnikrishnan B, Rekha T, Mithra P, Kulkarni $\mathrm{V}$, et al. Perceptions and practices of selfmedication among medical students in coastal South India. PLoS One 2013;8:e72247.

11. Lukovic JA, Miletic V, Pekmezovic T, Trajkovic G, Ratkovic N, Aleksic D, et al. Self-medication practices and risk factors for self-medication among medical students in Belgrade, Serbia. PLoS One 2014; 9:e114644.

\section{Authors Contribution:}

PRS was involved in conceptualizing the study, using the questionnaire, from a previous study analyzing the data, reviewing the literature, writing the manuscript and revising it for intellectual content. AKD helped in study conceptualization, review of literature, writing the manuscript and reviewing versions for critical intellectual issues. NRD helped in conceptualizing the study, conduct of the study, review of literature and writing the manuscript. AN was involved in study conceptualization, collecting the data, analysis of data and helped in writing the manuscript. BB helped in review of literature, collection of data and writing and revising the manuscript.

Source of Support: Nil, Conflict of Interest: None declared. 